\title{
Construindo saberes sobre a separação dos resíduos sólidos na Educação Infantil
}

\author{
Construyendo conocimientos sobre la separación de los residuos sólidos \\ en la educación infantil
}

\author{
Building knowledge on solid waste separation in Early Childhood \\ Education
}

\author{
Andreia Domingues Bitencourte ${ }^{1}$ \\ Rita de Cássia Morem Cóssio Rodriguez ${ }^{2}$
}

\begin{abstract}
Resumo
O presente artigo desenvolveu-se dentro do Programa de Pós Graduação em Ensino de Ciências e Matemática (PPGECM) - Mestrado Profissional pela Universidade Federal de Pelotas (UFPEL) e apresenta um relato de uma atividade desenvolvida em sala de aula com uma turma de Educação Infantil - Berçário II em uma Escola Municipal na Cidade de Pelotas/RS, sobre a Importância de construir saberes desde a Educação Infantil para a separação dos resíduos sólidos, a partir de personagens já conhecidos dos Desenhos Animados. Nesse estudo de natureza qualitativa (Ludke \& André 1986) procuramos investigar como as famílias dos alunos abordavam a questão do descarte dos Resíduos Sólidos. A metodologia utilizada foi a Pesquisa-ação, apoiado nos estudos de Gil (2002), e nos três momentos pedagógicos (Delizoicov 2011) tendo como instrumento de coleta de dados, o questionário. A análise dos resultados deu-se pela análise descritiva (Gil 2002) através da observação da apropriação do conhecimento pelo aluno, a partir do momento que o aluno identifica suas embalagens e destinaas aos locais de descarte correto e ainda quando esse dissemina esse conhecimento em casa aos seus familiares, vigiando as rotinas de descarte no seu lar e questionando sobre a reciclagem desses materiais e também pela análise dos questionários anteriores e após a aplicação da proposta.
\end{abstract}

Palavras-Chave: Desenhos animados; Conscientização; Reciclagem; Berçário II

\section{Resumen}

El presente artículo se desarrolló dentro del Programa de Posgrado en Enseñanza de Ciencias y Matemáticas (PPGECM) - Maestría Profesional por la Universidad Federal de Pelotas (UFPEL) y presenta un relato de una actividad desarrollada en el aula con una clase de Educación Infantil - Cacería II en una Escuela Municipal en la Ciudad de Pelotas / RS, sobre la Importancia de construir saberes desde la Educación Infantil para la separación de los residuos sólidos, a partir de personajes ya conocidos de los Dibujos Animados. En este estudio de naturaleza cualitativa (Ludke \& André 1986) buscamos investigar cómo las familias de los alumnos abordaban la cuestión del descarte de los Residuos Sólidos. La metodología utilizada fue la Investigación-acción, apoyado en los estudios de Gil (2002), y en los tres momentos pedagógicos (Delizoicov 2011) teniendo como instrumento de recolección de datos, el cuestionario. El análisis de los resultados se dio por el análisis descriptivo (Gil 2002) a través de la observación de la apropiación del conocimiento por el alumno, a partir del momento que el alumno identifica sus envases y destina a los locales de descarte correcto y aún cuando éste disemina ese conocimiento en casa a sus familiares, vigilando las rutinas de descarte en su hogar y cuestionando sobre el reciclaje de esos materiales y también por el análisis de los cuestionarios anteriores y después de la aplicación de la propuesta.

Palabras claves: Dibujos animados; la conciencia; reciclaje; Cuna II

\footnotetext{
${ }^{1}$ Mestranda em Educação em Ciências. Escola Superior de Educação do Instituto Politécnico de Bragança, ESE/IPB, Portugal; deiabitencourte@gmail.com

${ }_{2}^{2}$ Pós-doutorada em Educação - Estudos da Criança, pelo Instituto de Educação da Universidade do Minho, Portugal; rita.cossio@gmail.com
} 


\begin{abstract}
This article was developed within the Graduate Program in Teaching Science and Mathematics (PPGECM) Professional Master's Degree from the Federal University of Pelotas (UFPEL) and presents an account of an activity developed in a classroom with a class of Early Childhood Education - Nursery II at a Municipal School in the City of Pelotas / RS, on the Importance of building knowledge from Child Education to the separation of solid waste, from characters already known in the Cartoon. In this qualitative study (Ludke \& André 1986) we tried to investigate how the families of the students approached the issue of solid waste disposal. The methodology used was Action Research, supported by the studies of Gil (2002), and in the three pedagogical moments (Delizoicov 2011) with the questionnaire as a data collection instrument. The analysis of the results was done through the descriptive analysis (Gil 2002) through the observation of the appropriation of the knowledge by the student, from the moment the student identifies their packaging and destines them to the correct disposal sites and even when this disseminates this knowledge at home to their families, monitoring the routines of disposal in their home and questioning the recycling of these materials and also the analysis of previous questionnaires and after the application of the proposal.
\end{abstract}

Keywords: Cartoon; Awareness; Recycling; Nursery II

\title{
1. Introdução
}

A atividade que deu forma ao desenvolvimento do Projeto Lixo é no Lixo foi pensada, a partir da importância da conscientização sobre o descarte correto do Lixo (resíduos sólidos), desde a Educação Infantil.

È primordial que esse tema seja apresentado e construído na prática pelos alunos, assim eles aprendem e disseminam esse conhecimento em casa e na família.

No primeiro momento para construirmos a conscientização sobre a separação do lixo, ou seja, sobre a reciclagem desses materiais, apresentamos e assistimos juntos "Desenhos Animados", que foram convidativos e próximos da concepção e do entendimento dos alunos (por faixa etária), construindo assim a prática efetiva da reciclagem, tornando-se um tema acessível para o cotidiano escolar e do lar.

O objetivo geral da proposta é despertar nos alunos a consciência de que praticamente todo o lixo pode ser reaproveitado e fazê-los disseminadores desse conhecimento.

Os objetivos específicos são identificar a importância de colocar o lixo no lixo; conhecer o lixo que fabricamos; reconhecer a necessidade da separação do lixo; identificar os tipos de materiais recicláveis; conhecer as cores que classificam cada tipo de lixo (orgânico, plástico, metal, vidro e papel) e construir brinquedos: com materiais recicláveis.

Com a grande influência da televisão na vida das crianças, nada melhor que utilizar o poder de marketing de alguns personagens queridinhos das crianças e facilitar o aprendizado, tendo em vista que as crianças diariamente estão expostas às diversas mídias. 
A partir disso nos utilizaremos das mídias televisivas, no caso os desenhos da Peppa Pig e do Peixonauta para abordamos um tema de fundamental relevância para todos e que precisa ser discutido desde a Educação Infantil que é a Importância da Reciclagem do Lixo. Para SILVA (2007, p. 11):

É preciso que a escola evidencie em seu projeto educativo que aquilo que a criança vivencia fora da sala de aula também educa. As relações interpessoais nas famílias e comunidades, a forma como os adultos tratam as crianças, a forma de lidar com a limpeza ou com o lixo, entre outros, representam situações de ensino e aprendizagem.

Por isso, precisamos despertar no aluno a consciência de que praticamente todo o lixo pode ser reaproveitado, ensinando-o a identificar a importância de colocar o lixo no lixo, de conhecer o lixo que fabricamos; de reconhecer a necessidade da separação do lixo e identificar os tipos de materiais recicláveis, classificando cada tipo de lixo (orgânico, plástico, metal, vidro e papel), podendo inclusive, ser usado na confecção de ricos e criativos materiais didáticos que servirão de instrumentos para enriquecer as aulas, facilitando assim, o processo ensino e aprendizagem e também podendo ser usado para confecção de brinquedos com materiais recicláveis, e assim torna-lo um disseminador de conhecimentos, pois quando o adulto é fiscalizado pela criança, esse passa a rever suas atitudes.

OLIVEIRA (1997, p.25), afirma que “a Educação Ambiental deve estar fundamentada na mudança de percepção dos seres humanos em relação à natureza". Ela deve transformar a visão utilitarista dos recursos naturais em atitudes, valores e ações capazes de frear o acelerado processo de deterioração do meio ambiente. No cenário presente, a missão de BRASIL e SANTOS (2004, p.01) é um estimulante reforço para as crenças ambientalistas.

Elas constataram que:

muitas das agressões cometidas contra o habitat resultam da falta de informação, sinônimo de ignorância. Aliás, a causa primeira da dilapidação do patrimônio natural no Brasil é a conjugação de dois fatores: a cupidez, de quem só enxerga o lucro a qualquer custo e a ignorância conduta de quem aparenta desconhecer os resultados da insensatez praticada contra a natureza.

O artigo de Trindade - Consciência Ambiental vem reforçar nossa pratica no sentido de que, na pesquisa elaborada por ela e publicada na Enciclopédia Biosfera, Centro Científico Conhecer - Goiânia, vol.7, N.12; 2011 reforça a importância de esse tema ser discutido cada vez mais cedo, ou seja, desde a Educação infantil, ampliando a compreensão das crianças da 
importância que deve-se ter com o descarte dos resíduos e da importância da reciclagem da maioria dos materiais descartados.

\section{Metodologia}

O estudo de natureza qualitativa (Ludke \& André, 1986, p.13), utilizou como metodologia a pesquisa-ação, apoiado nos estudos de Gil (2002, p.143), perpassando pelos três momentos pedagógicos, segundo Delizoicov (2011).

Esse estudo foi desenvolvido em uma turma de Berçário II, (Idades entre um e dois anos não completos até o final do Mês de Março do referido ano letivo), de uma Escola Municipal de Educação Infantil na Cidade de Pelotas/RS, onde apresentamos primeiro os vídeos da Peppa $\mathrm{Pig}^{3}$ e Peppa $\mathrm{Pig}^{4}$ e do Peixonauta ${ }^{5}$.

Durante a exibição dos vídeos, fizemos alguns questionamentos aos alunos, sobre o que estão assistindo, onde os personagens estão e o que estão descartando.

Em paralelo, solicitamos as famílias que autorizassem, por meio de um Termo de Consentimento o uso dos dados, fotos, vídeos e demais registros das atividades pedagógicas desenvolvidas e enviamos um questionário semiaberto para as famílias, questionando sobre os hábitos de descarte do Lixo reciclável, ou como usualmente é chamado: "Resíduos Sólidos”, e solicitamos que nos enviassem pelos alunos, embalagens vazias de quatro tipos, são elas: papel, metal, vidros e plásticos.

Nos questionários a maioria das famílias respondeu que não costumam separar os resíduos sólidos, outras famílias afirmam fazerem a seleção, porém reclamam da falta de informação sobre a destinação correta e coleta desses resíduos para reciclagem.

\footnotetext{
${ }^{3}$ Coleta seletiva Peppa Pig. Disponível em: https://www.youtube.com/watch?v=T0T3mjLzwWc. Acesso em: 05 jun 18.

${ }^{4}$ Peppa Pig Reciclando, disponível em https://www.youtube.com/watch?v=CC-AR1d-IDw\&feature=youtu.be. Acesso em 05 jun 2018.

${ }^{5}$ Peixonauta, O caso da garrafa pet. Disponível em: https://www.youtube.com/watch?v=9uwZHC-ui_Y. Acesso em: 05 jun 18.
} 


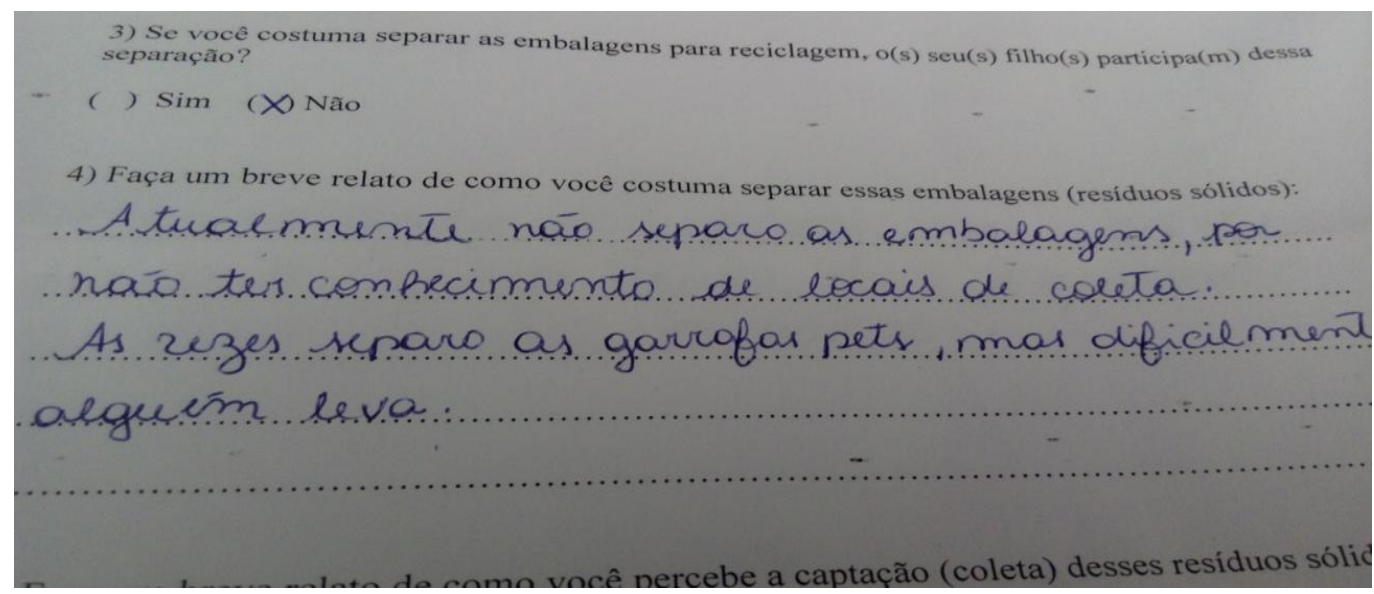

Figura 1 - Resposta da família1 - Questionário inicial Fonte: Acervo da Autora - 2018

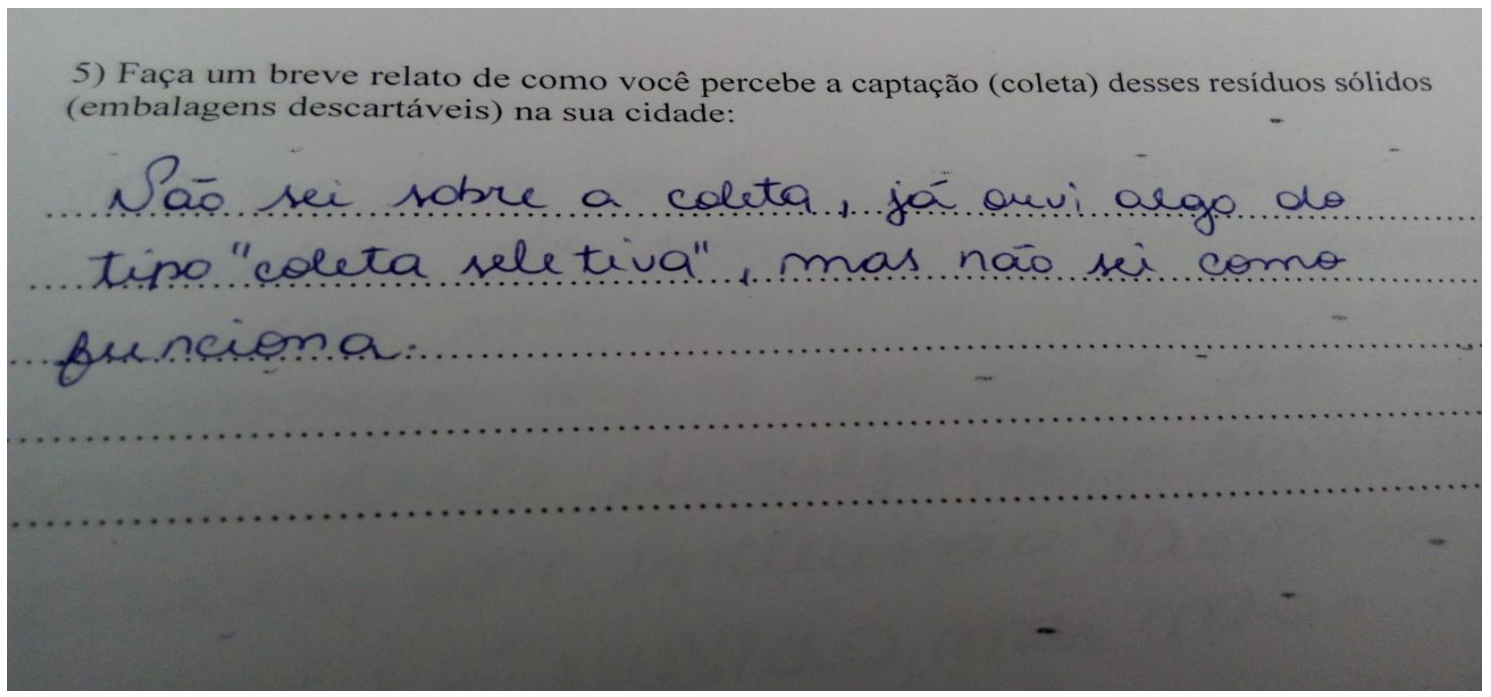

Figura 2 - Resposta da família 2 - Questionário inicial Fonte: Acervo da Autora - 2018

A partir destes, fizemos uma conversa com os alunos, a fim de que eles conheçam o lixo que descartamos diariamente em nossas casas e na escola.

Chamamos a atenção sobre a importância de colocar o lixo no lixo; e também para a necessidade da separação desses resíduos sólidos e da identificação dos materiais recicláveis como: plásticos, metais, vidros e papeis e também sobre a separação do lixo orgânico.

Salientamos que cada tipo de lixo tem uma lixeira correspondente para cada material como eles puderam perceber no desenho animado que assistimos anteriormente.

Construímos em sala de aula as lixeiras nas cores correspondentes (Vermelha para o descarte dos plásticos, Amarela para o descarte dos metais, Verde para o descarte dos vidros e Azul para o descarte dos papéis) e cada aluno pode dar sua contribuição na pintura dessas. 
RELACult - Revista Latino-Americana de Estudos em Cultura e Sociedade

Revista Latinoamericana de Estudios en Cultura y Sociedad | Latin American Journal of Studies in Culture and Society V. 05, ed. especial, abr., 2019, artigo no 1292| claec.org/relacult | e-ISSN: 2525-7870

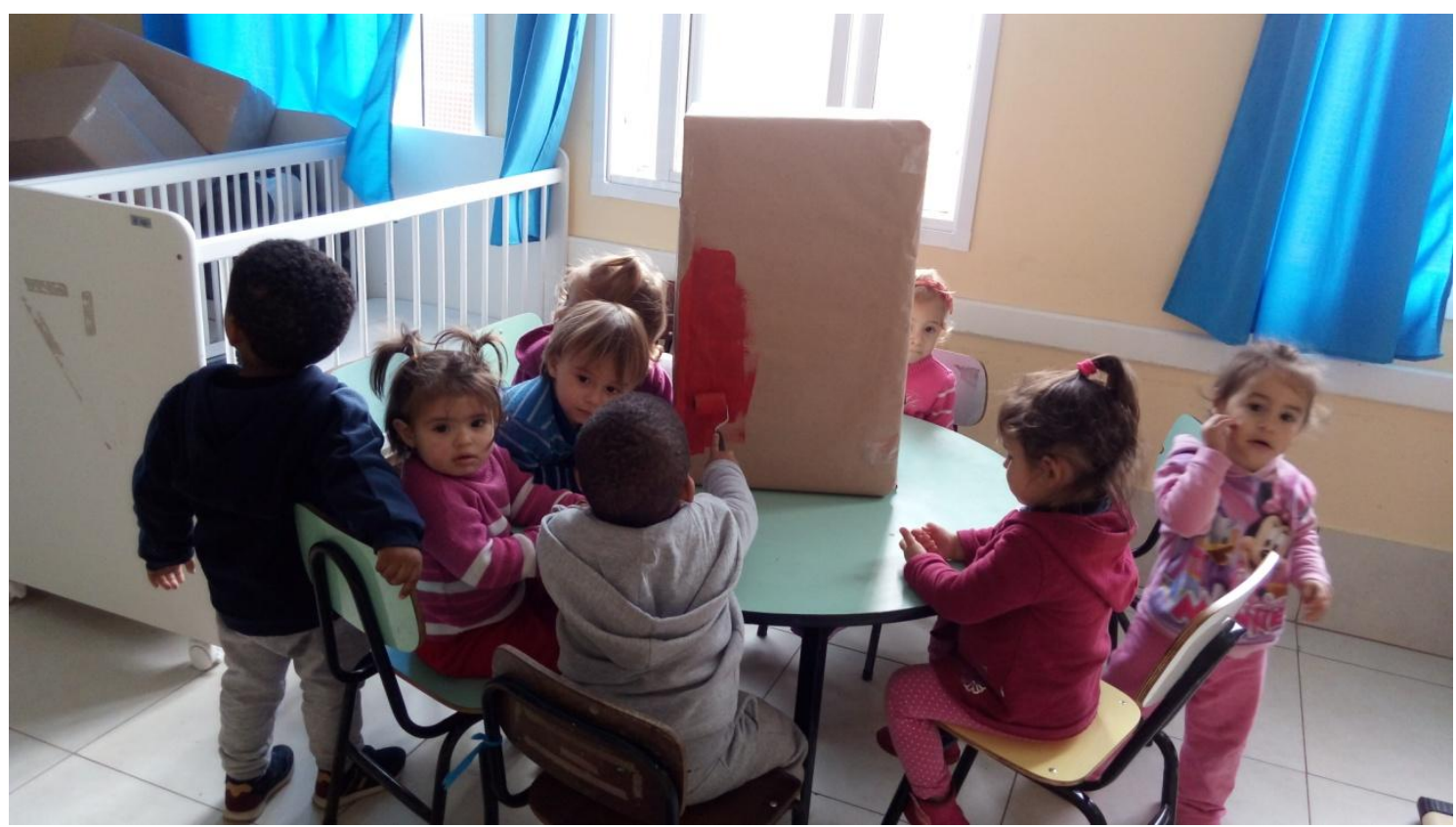

Figura 3 - Construindo a Lixeira Vermelha para descarte de plásticos Fonte: Acervo da Autora - 2018

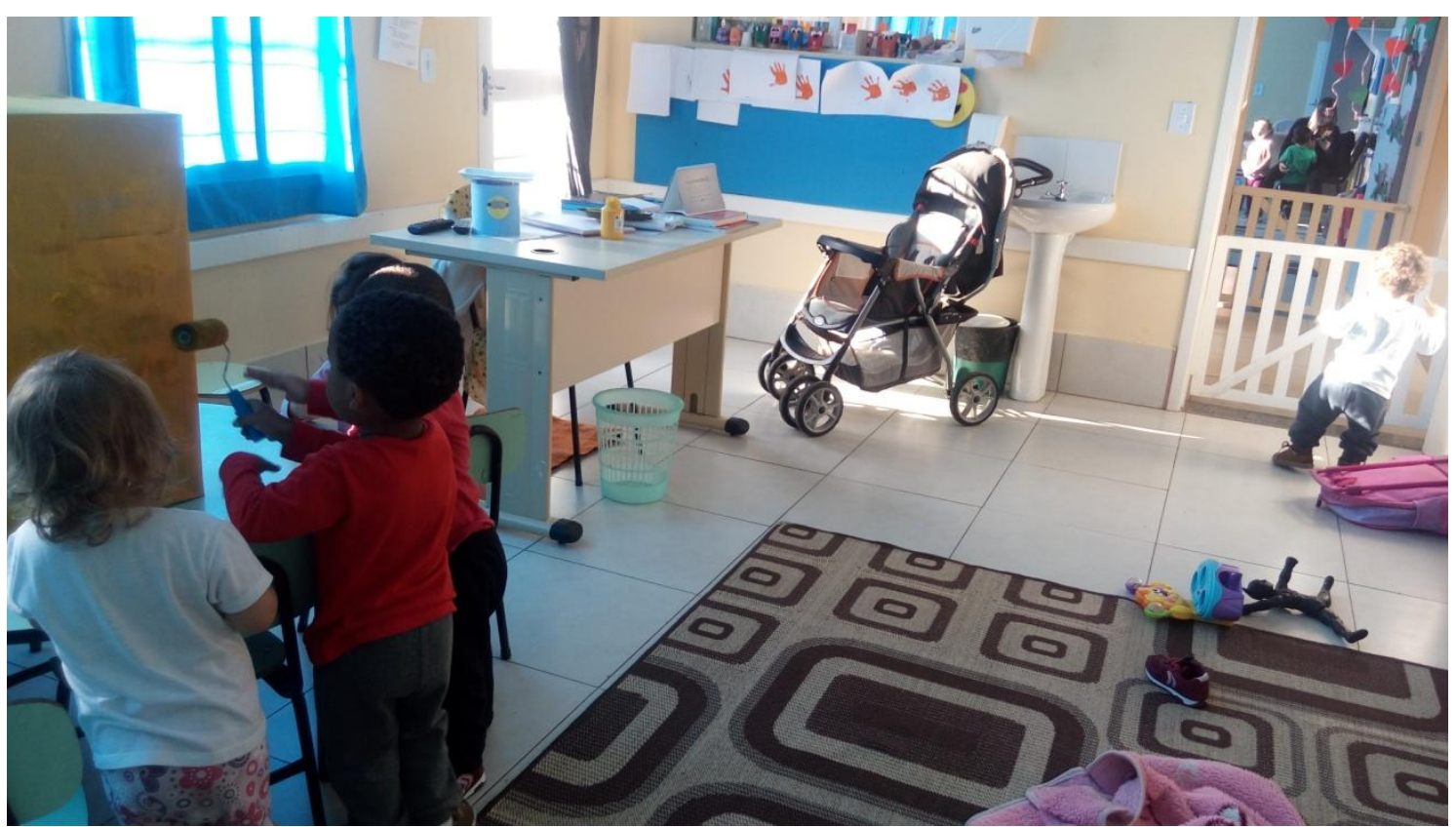

Figura 4 - Construindo a Lixeira Amarela para descarte de metais Fonte: Acervo da Autora - 2018 
RELACult - Revista Latino-Americana de Estudos em Cultura e Sociedade

Revista Latinoamericana de Estudios en Cultura y Sociedad | Latin American Journal of Studies in Culture and Society V. 05, ed. especial, abr., 2019, artigo no 1292| claec.org/relacult | e-ISSN: 2525-7870

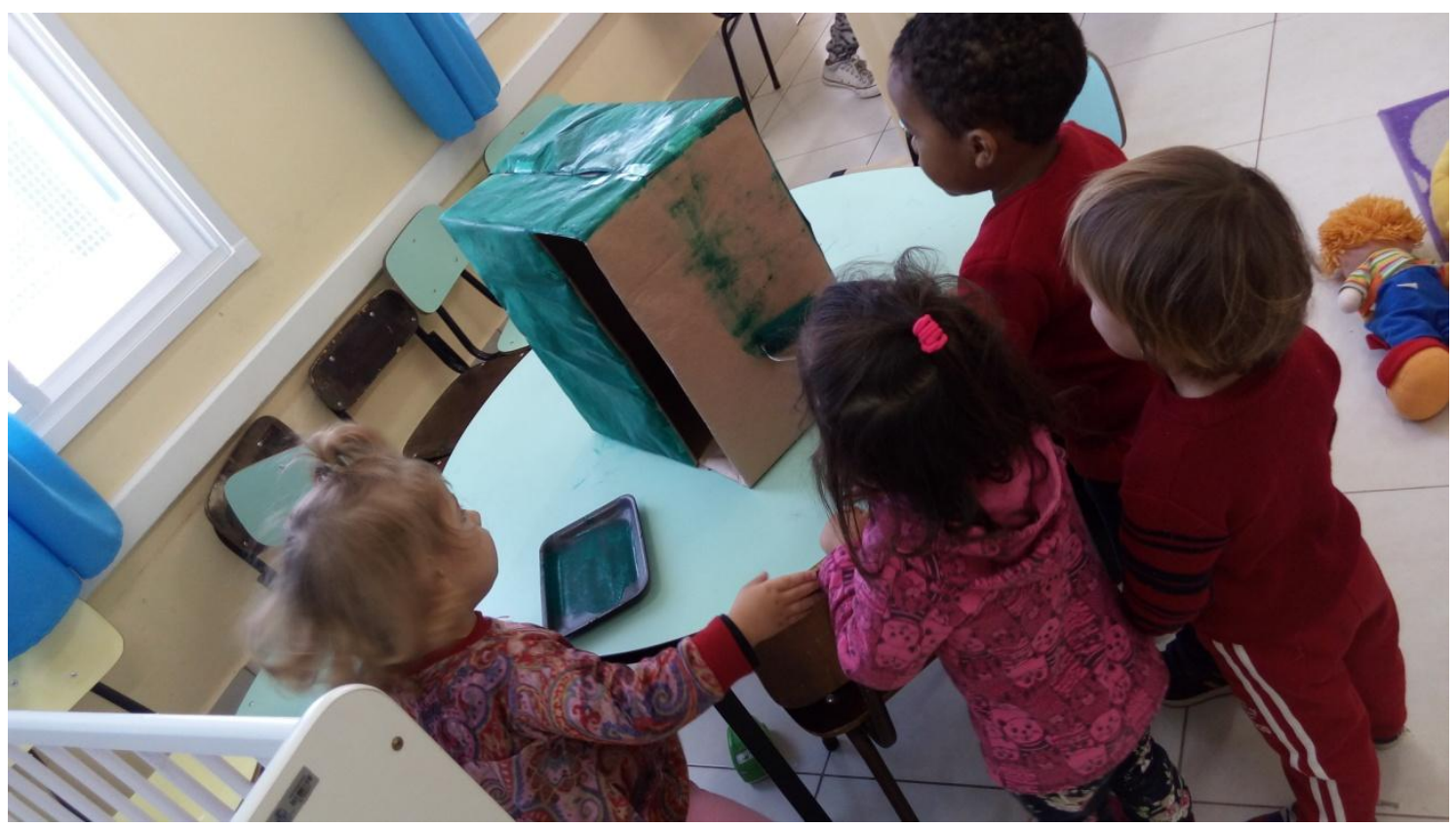

Figura 5 - Construindo a Lixeira Verde para descarte de vidros

Fonte: Acervo da Autora - 2018

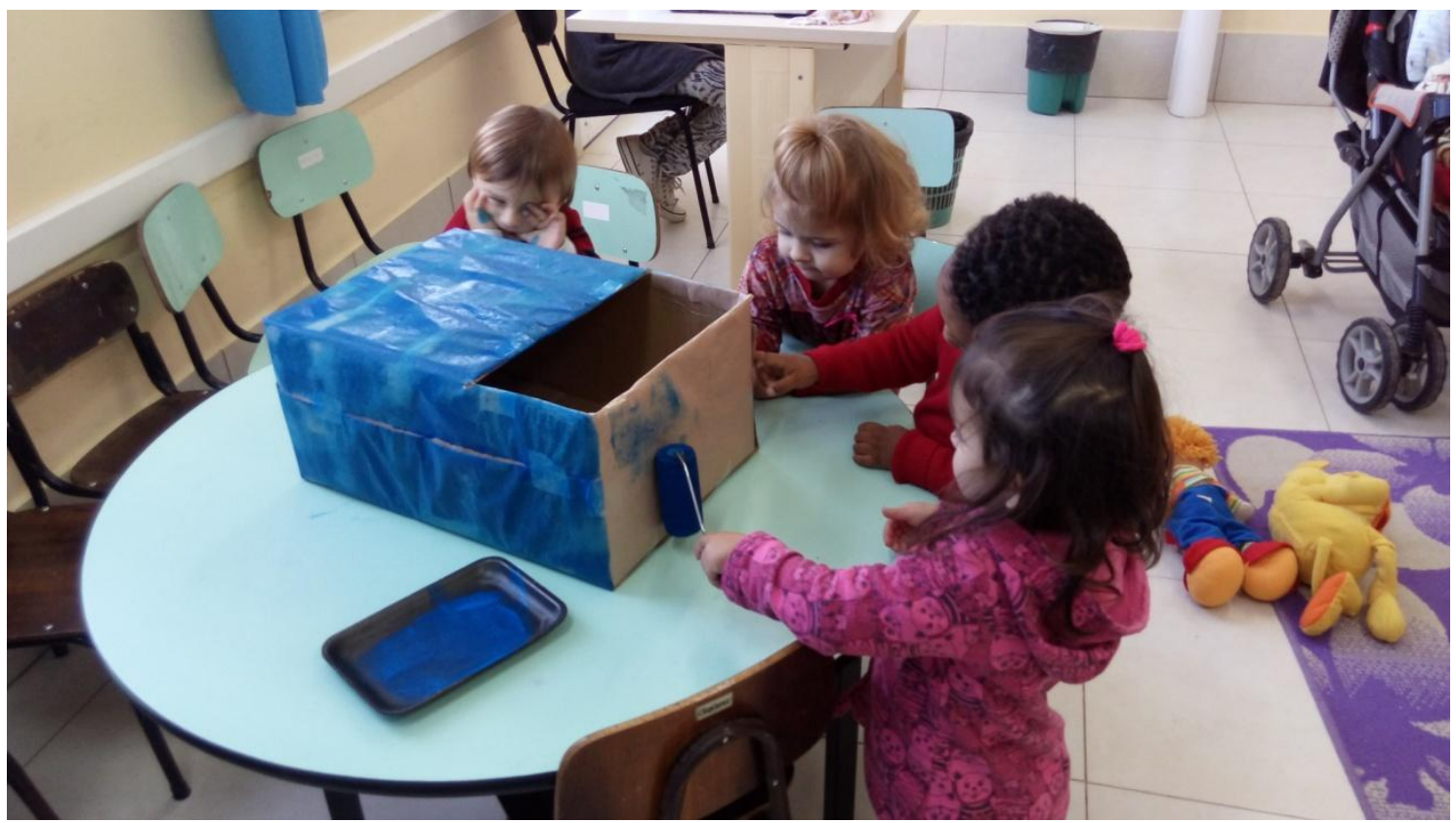

Figura 6 - Construindo a Lixeira Azul para descarte de papéis Fonte: Acervo da Autora - 2018

Posteriormente os alunos (um a um na sua vez) escolheram alguns materiais (resíduos sólidos) e o classificaram por tipo de lixo (material reciclado), colocando-o na lixeira correspondente ao tipo de reciclável, identificada pela cor correspondente, construída coletivamente pela turma. 


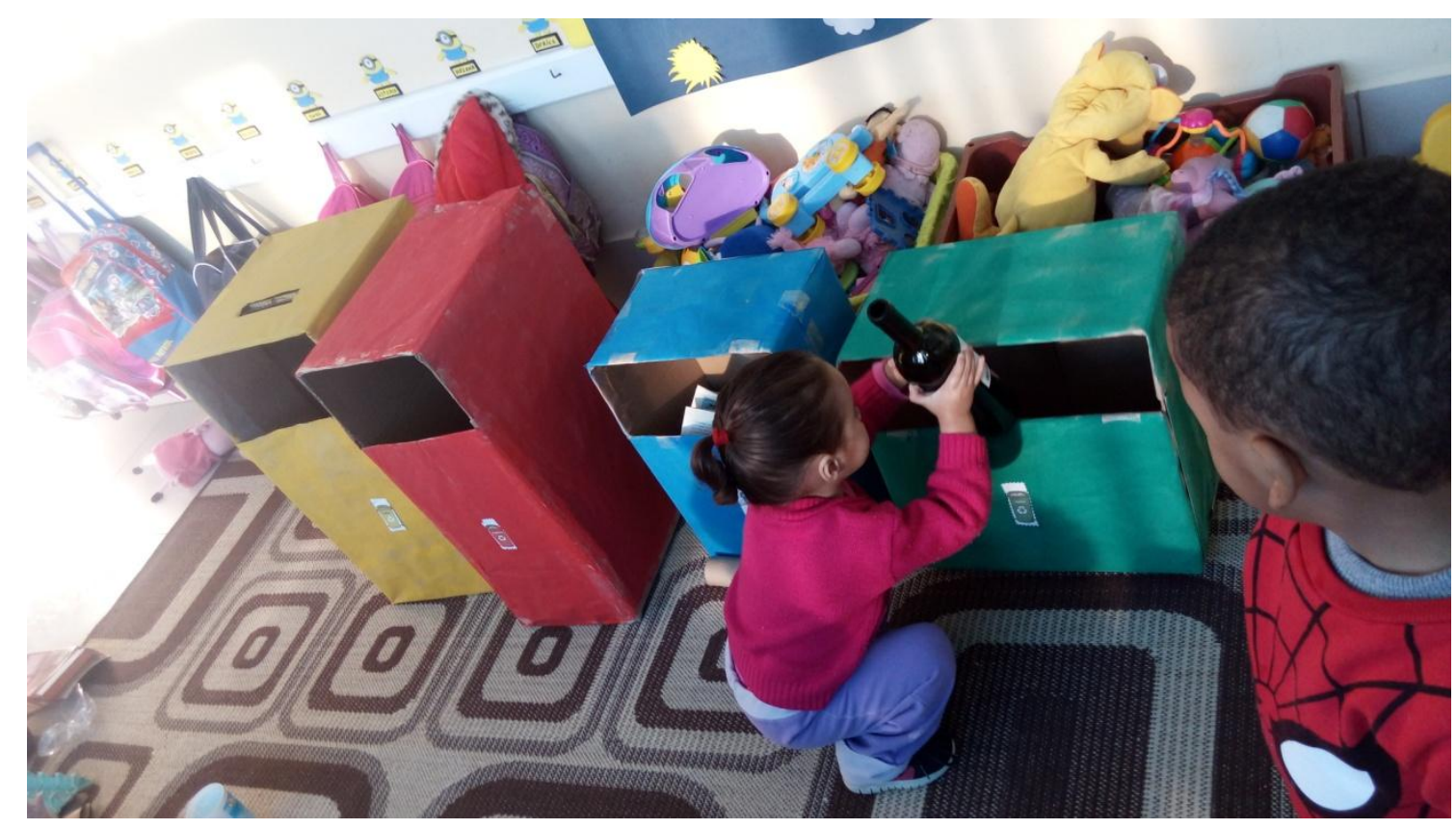

Figura 7 - Desenvolvimento da atividade

Fonte: Acervo da Autora - 2018

Após, a aplicação da atividade, aplicamos um novo questionário que foi enviado aos familiares, buscando saber como foi compartilhado o conhecimento do aluno aprendido na escola nas rotinas diárias do lar, se o aluno interferiu e orientou os familiares com os conhecimentos escolares, que foi analisado pelo método de análise descritiva (Gil 2002, p.146).

A avaliação dos resultados, deu-se através da análise descritiva (Gil 2002, p.146), através da análise dos questionários iniciais, observação do desenvolvimento das atividades propostas e da análise dos questionários finais aplicados às famílias, onde podemos constatar que os alunos apropriaram-se do conhecimento, através da participação efetiva no desenvolvimento do projeto. 
RELACult - Revista Latino-Americana de Estudos em Cultura e Sociedade

Revista Latinoamericana de Estudios en Cultura y Sociedad | Latin American Journal of Studies in Culture and Society V. 05, ed. especial, abr., 2019, artigo no 1292| claec.org/relacult | e-ISSN: 2525-7870

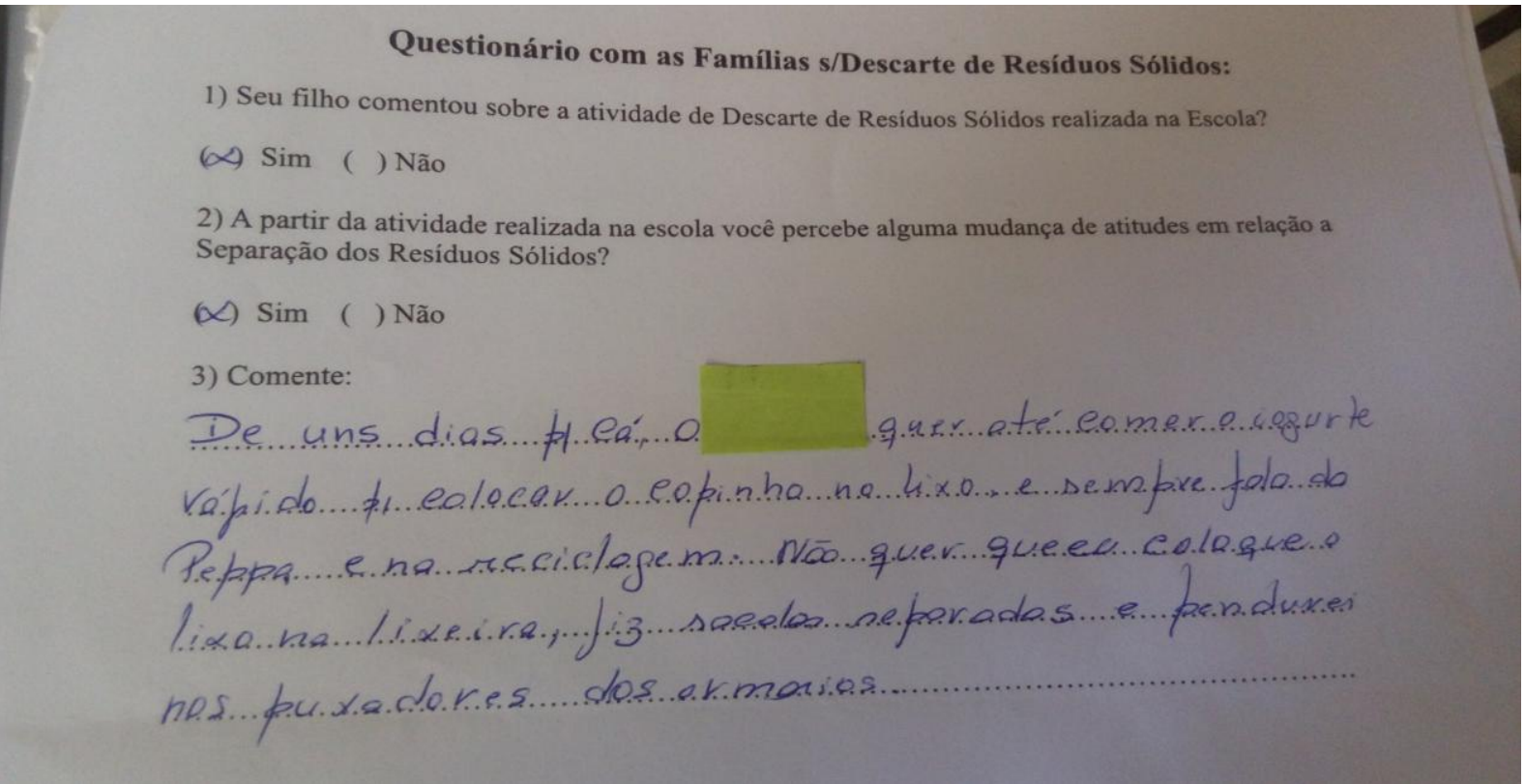

Figura 8 - Resposta de uma das famílias após a aplicação da atividade Fonte: Acervo da Autora - 2018

Por fim, selecionaremos alguns materiais para a confecção de brinquedos e outros materiais pedagógicos, como caixa de leite para a construção de sanfonas e animais, cachorros por exemplo. Rolos de papel higiênico para a confecção carrinhos e jogos da memória. Garrafas pet, para plantarmos flores e sementes, e também os fundos dessas para a confecção de flores para decoração de vasos e jardins.

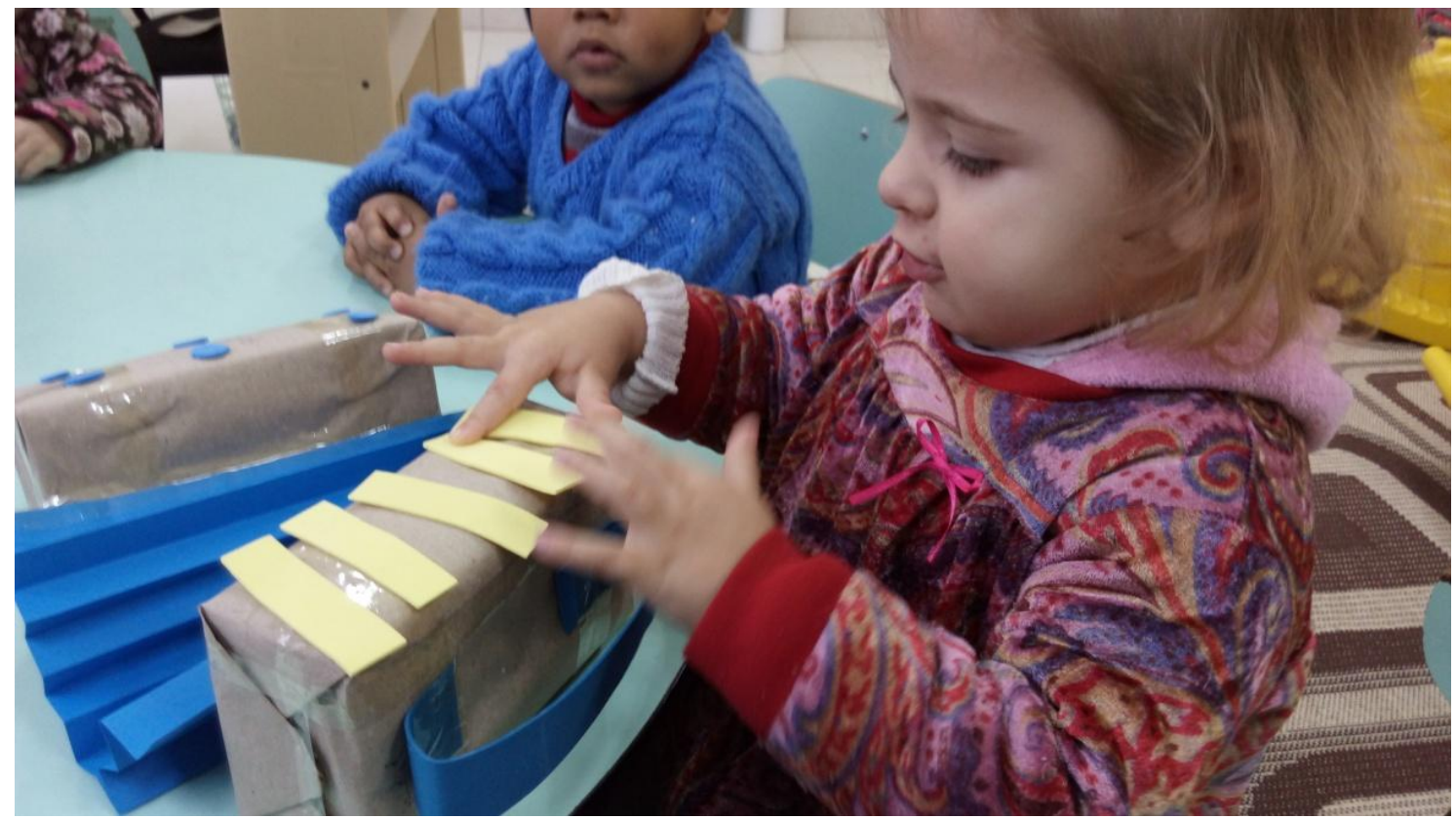

Figura 9 - Confecção de Sanfona a partir de caixas de Leite

Fonte: Acervo da Autora - 2018 
RELACult - Revista Latino-Americana de Estudos em Cultura e Sociedade

Revista Latinoamericana de Estudios en Cultura y Sociedad | Latin American Journal of Studies in Culture and Society V. 05, ed. especial, abr., 2019, artigo no 1292| claec.org/relacult | e-ISSN: 2525-7870

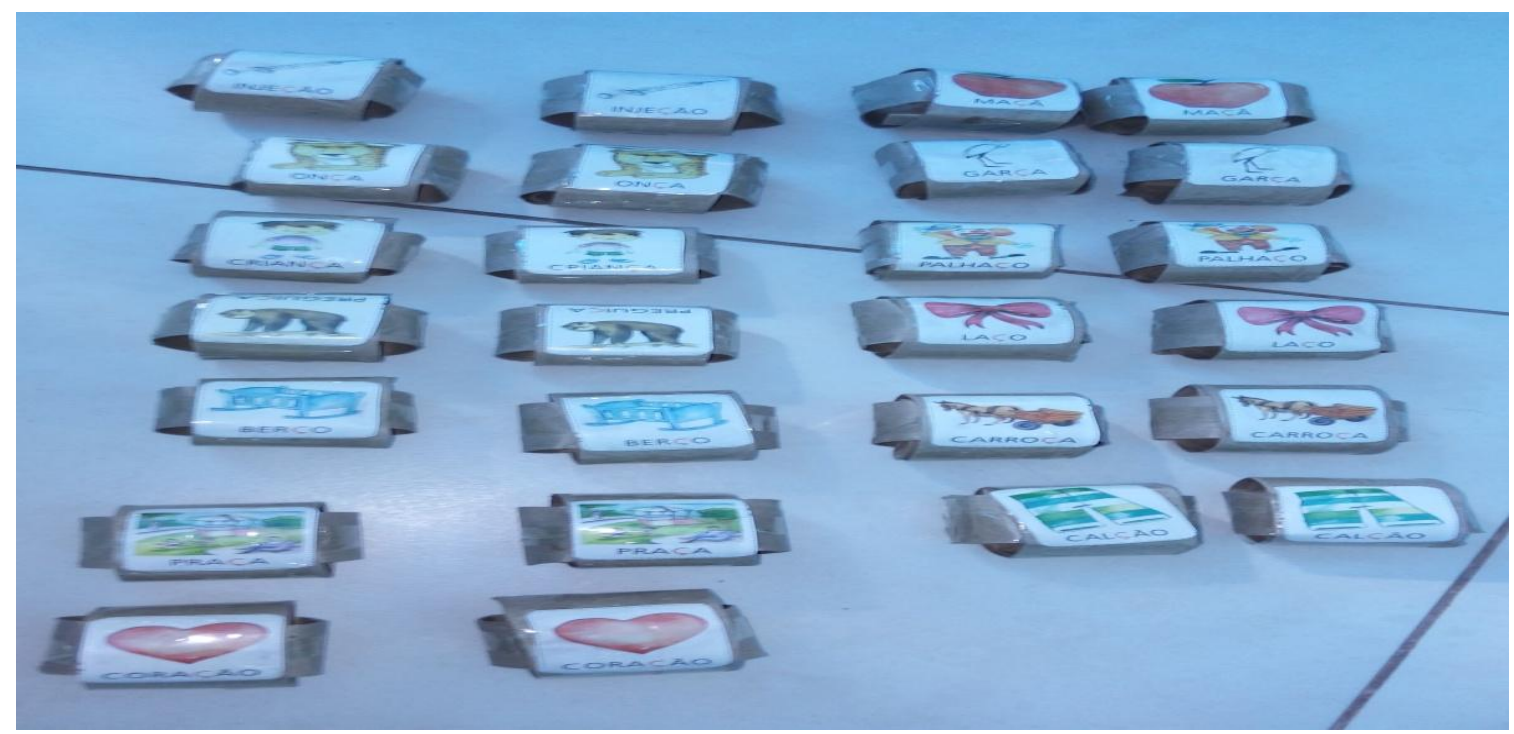

Figura 10 - Confecção de Jogo da memória a partir de rolos de papel Fonte: Acervo da Autora - 2018

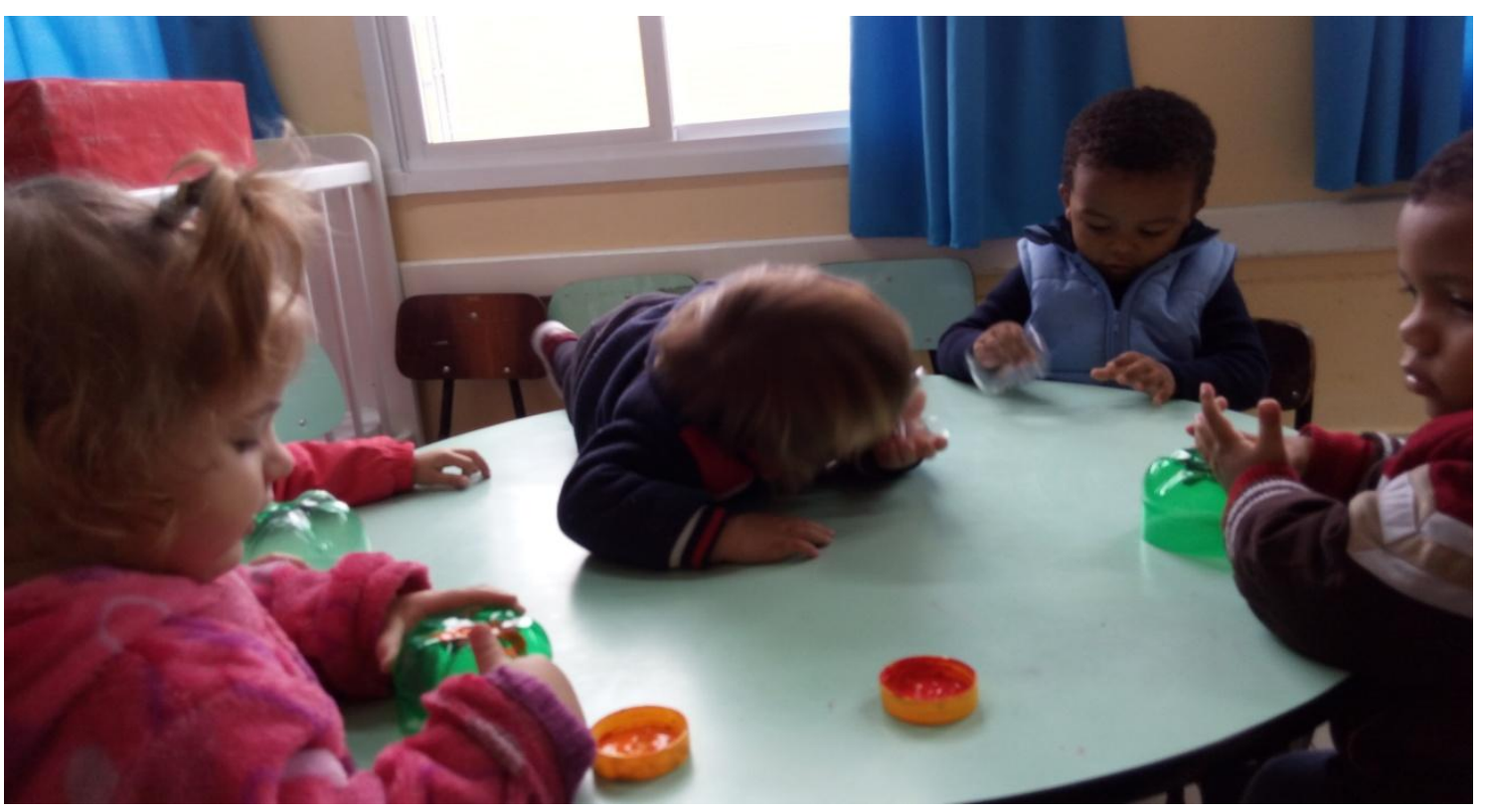

Figura 11 - Confecção de Flores a partir de fundos de garrafas pet's Fonte: Acervo da Autora - 2018

\subsection{Resultados}

Analisando os questionários iniciais a maioria dos pais relatou que os alunos não participam da seleção dos materiais recicláveis em casa, e a maioria dos pais não selecionava por tipo de material reciclável para o descarte.

Com a aplicação da atividade em sala de aula, podemos perceber que os alunos reconheciam os resíduos sólidos que trouxeram de casa e inclusive, na hora de procura-los 
para descarte nas lixeiras correspondentes, procuravam pegar os que tinham trazido e ainda faziam comentários sobre o resíduo sólido que pegavam, mostrando que realmente lhe era familiar.

Também podemos perceber através da atividade em sala de aula que eles, após assistirem os vídeos sobre o descarte correto e com os questionamentos e orientação da professora, conseguiram destinar os resíduos sólidos corretamente nas lixeiras.

Pela análise dos questionários finais, podemos perceber que embora eles não se expressem de forma oral claramente, eles internalizaram o conhecimento e contribuíram para que as famílias selecionassem os resíduos sólidos a partir da atividade desenvolvida na escola.

Em um dos relatos a família informa que precisou fazer a separação dos resíduos com sacolas plásticas penduradas nos puxadores dos armários, pois o aluno não quer que descarte no lixo comum e sempre refere-se a Peppa e a Reciclagem, querendo inclusive, alimentar-se rápido para fazer o descarte do resíduo sólido.

Em outro relato, a família nos contou que surpreendeu o aluno fazendo a seleção dos resíduos na lixeira comum de casa, onde ele tinha selecionado por categorias os resíduos sólidos que encontrou, empilhando-os e que como não se expressa oralmente de forma clara, dizia a família que era a Peppa, onde a mãe por estar envolvida com as atividades escolares, tanto pelos questionários, como também tendo participado no envio de materiais recicláveis para a atividade escolar, percebeu que então, o aluno estava fazendo a seleção dos resíduos sólidos.

\section{Considerações Finais}

Contatou-se que mesmo com a participação dos pais nos questionários e no envio de resíduos sólidos para a escola, é necessária a participação mais efetiva da família nas atividades escolares, para que possam socializar os conhecimentos da criança e com a criança, podendo compreender o que está sendo elaborado e trabalhado em sala de aula, facilitando assim a conversação, a interpretação das atitudes e a troca de experiências.

Sendo assim, podemos perceber que a apropriação dos conhecimentos pelos alunos, deu-se através da prática efetiva do descarte correto dos materiais nas lixeiras correspondentes em sala de aula, pela conscientização da importância da reciclagem através dos personagens dos desenhos animados e das informações que recebeu na escola, e que esses conhecimentos foram reproduzidos nas famílias, tornando-os "Pequenos fiscais do meio ambiente". 


\section{Referências}

BRASIL, A. M. SANTOS, F. Equilíbrio Ambiental e Resíduos na sociedade moderna. São Paulo: FAARTE Editora, 2004. (ISBN 85-98847-01-1).

DELIZOICOV, D.; ANGOTTI, J. A.; PERNAMBUCO, M. M. Ensino de ciências: fundamentos e métodos. São Paulo: Cortez, 2002.

GIL, Antônio Carlos, 1946-Como elaborar projetos de pesquisa/Antônio Carlos Gil. - 4. ed. São Paulo: Atlas, 2002.

LUDKE, M., André, M. Pesquisa em Educação: abordagens qualitativas.São Paulo: EPU, 1986.

OLIVEIRA, G. P. de. Educação Ambiental voltada para a formação profissional na área ambiental e florestal. Piracicaba, ESALQ, 1997. (Dissertação para obtenção do título de Mestre na área de Ciências Florestais).

SILVA, D. T. S. Educação Ambiental: Coleta Seletiva e Reciclagem de Resíduos Sólidos na Escola. Cachoeirinha-RS: FASB, 2007.

TRINDADE, Naianne A. Dias - Consciência Ambiental: Coleta Seletiva e reciclagem no Ambiente Escolar. Disponível em http://www.conhecer.org.br/enciclop/2011a/humanas/consciencia\%20ambiental.pdf. Acesso em 05 jun 2018. 